08

\title{
Направленное излучение из квантовых точек GaAs в теле нитевидных нанокристаллов AIGaAs
}

\author{
() Р.P. Резник ${ }^{1}$, К.М. Морозов ${ }^{1}$, И.Л. Крестников ${ }^{1}$, К.П. Котляр ${ }^{2}$, И.П. Сошников ${ }^{3-5}$, L. Leandro $^{6}$, \\ N. Akopian $^{6}$, Г.Э. Цырлин ${ }^{2-5,7}$ \\ ${ }^{1}$ Innolume GmbH, Dortmund, Germany \\ ${ }^{2}$ Санкт-Петербургский государственный университет, Санкт-Петербург, Россия \\ ${ }^{3}$ Санкт-Петербургский национальный исследовательский Академический университет им. Ж.И. Алфёрова РАН, \\ Санкт-Петербург, Россия \\ ${ }^{4}$ Физико-технический институт им. А.Ф. Иофрфе РАН, Санкт-Петербург, Россия \\ ${ }^{5}$ Институт аналитического приборостроения РАН, Санкт-Петербург, Россия \\ ${ }^{6}$ DTU Fotonik, Kongens Lyngby, Denmark \\ ${ }^{7}$ Университет ИТМО, Санкт-Петербург, Россия \\ E-mail: moment92@mail.ru
}

Поступило в Редакцию 18 января 2021 г.

В окончательной редакции 27 января 2021 r.

Принято к публикации 27 января 2021 r.

Приводятся результаты экспериментальных исследований направленности излучения из квантовых точек $\mathrm{GaAs}$ в нитевидных нанокристаллах $\mathrm{AlGaAs}$, выращенных методом молекулярно-пучковой эпитаксии на поверхности кремния. Показано, что интенсивность излучения из квантовых точек в направлении роста нитевидных нанокристаллов на два порядка превышает интенсивность излучения в перпендикулярном направлении.

Ключевые слова: полупроводники, нитевидные нанокристаллы, квантовые точки, молекулярно-пучковая эпитаксия, микрофотолюминесценция, направленное излучение.

DOI: 10.21883/PJTF.2021.08.50855.18715

В настоящее время нитевидные нанокристаллы (ННК) привлекают все большее внимание исследователей благодаря возможности реализации на их основе различных приборных компонентов, в том числе солнечных элементов, зондов для сканирующей туннельной микроскопии, лазеров, светодиодов, транзисторов, детекторов, эмиссионных катодов и т. п. [1]. Использование такого технологического метода синтеза ННК, как метод молекулярно-пучковой эпитаксии (МПЭ) [2,3], позволило воспроизводимо получать наноструктуры с комбинированной размерностью, например типа „квантовая точка (КТ) в ННК“ [4-7]. В отличие от КТ, сформированных по механизму Странски-Крастанова [8], диаметр, высота и плотность таких КТ определяются диаметром ННК, временем роста и плотностью ННК соответственно. Благодаря эффективной релаксации механических напряжений на боковых гранях ННК подобные гибридные наноструктуры могут быть сформированы на поверхности кремния. Ранее было показано, что КТ GaAs в теле ННК $\mathrm{AlGaAs,} \mathrm{в} \mathrm{том} \mathrm{числе} \mathrm{выращенных} \mathrm{на} \mathrm{кремниевой} \mathrm{под-}$ ложке, являются эффективными источниками одиночных фотонов $[9,10]$, что указывает на перспективность их применения для квантовой криптографии. При этом как сами НHК AlGaAs, так и КT GaAs формировались в ранее малоизученной для этой системы вюрцитной кристаллографической фазе [11].

Для наиболее полного использования подобных наноструктур в оптоэлектронных приложениях исследование направленности излучения из КТ в теле ННК является критически важным [12]. Ранее для системы материалов $\mathrm{InP} / \mathrm{InAs}_{1-x} \mathrm{P}_{x}$ было показано, что ННК могут обладать волноводными свойствами для излучения из КТ, причем изменение отношения диаметра ННК к длине волны излучения из КТ приводит к изменению интенсивности излучения $[13,14]$.

В настоящей работе приведены результаты экспериментальных исследований направленности излучения из KT GaAs в теле НHK AlGaAs, выращенных методом МПЭ на поверхности кремния.

Эксперименты по росту массивов HНК AlGaAs c KT GaAs были выполнены с помощью установки МПЭ Riber Compact 21, оснащенной помимо ростовой камеры вакуумно-совмещенной камерой для нанесения $\mathrm{Au}$ (камера металлизации). В качестве подложек использовались полированные пластины кремния с ориентацией поверхности (111). Рост производился в несколько этапов. После удаления окисного слоя при температуре $850^{\circ} \mathrm{C}$ с поверхности подложки, предварительно обработанной в водном растворе $\mathrm{HF}(10: 1)$, температура образца понижалась до $550^{\circ} \mathrm{C}$ и производилось напыление пленки золота толщиной $\sim 0.1-0.2 \mathrm{~nm}$ в камере металлизации. После минутной выдержки для создания равномерных капель $\mathrm{Au}$ температура понижалась до комнатной, и образец переносился в ростовую камеру без нарушения условий сверхвысокого вакуума. В ростовой камере температура повышалась до $510^{\circ} \mathrm{C}$, затем открывались 

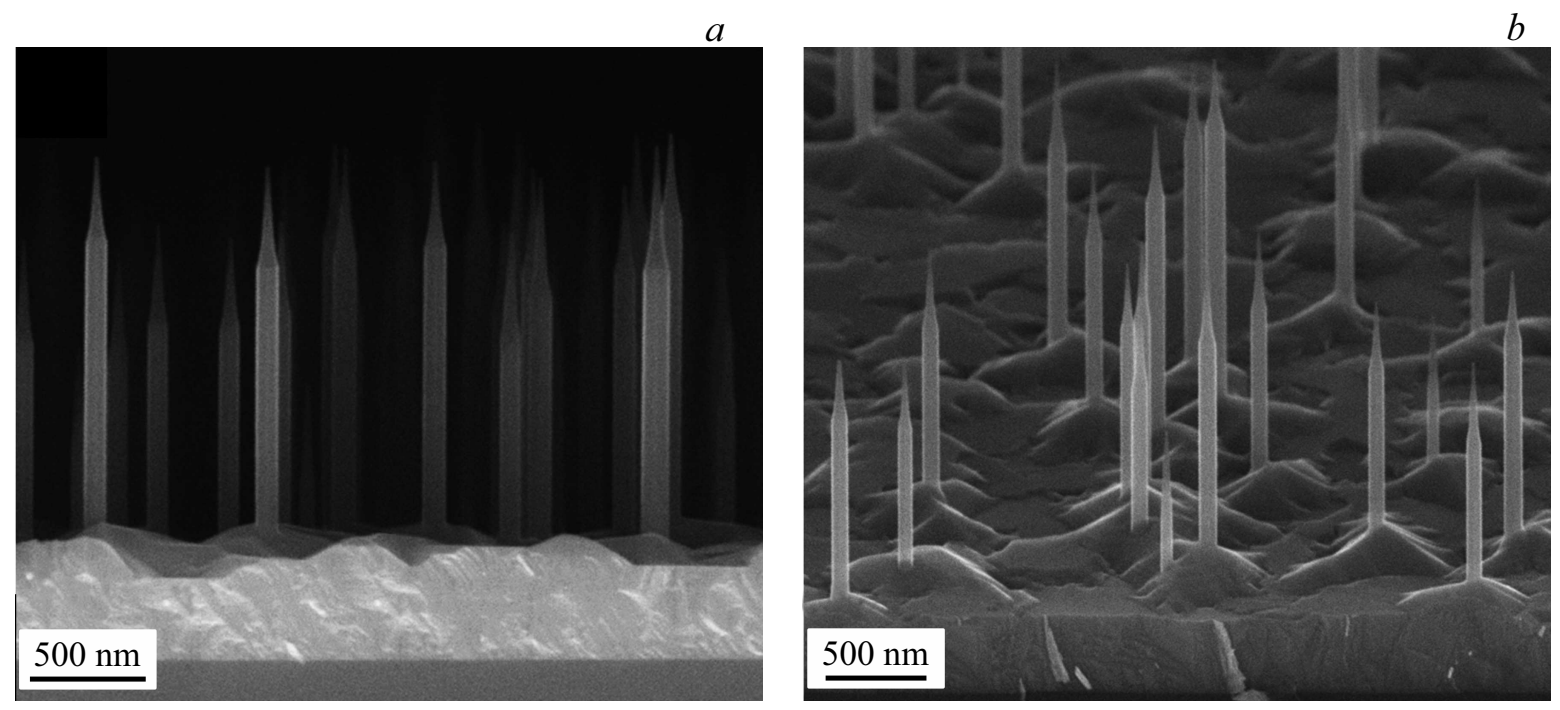

Рис. 1. Типичные РЭМ-изображения ННК AlGaAs с КТ GaAs, сформированных на поверхности $\mathrm{Si}(111)$. a - вид сбоку, $b-$ в изометрии.

заслонки $\mathrm{Al}$, Ga и As и проводилось выращивание ННК AlGaAs в течение 20 min в Аs-стабилизированных условиях. Картины дифракции быстрых электронов на отражение свидетельствовали об образовании уже после 1 min роста чистой вюрцитной кристаллографической фазы ННК, которая не менялась в течение всего процесса. На следующем этапе с помощью кратковременного закрытия заслонки источника Al были сформированы десять КT GaAs в теле ННК. Время формирования каждой КТ составило $15 \mathrm{~s}$ при времени роста AlGaAs между КТ $10 \mathrm{~s}$. На завершающем этапе заслонка источника $\mathrm{Al}$ открывалась на $5 \mathrm{~min}$ для формирования покрывающего слоя. Номинальный состав Al в твердом растворе, измеренный исходя из соотношения потоков для роста слоя на поверхности подложки $\mathrm{GaAs}(100)$, составил 0.3. Скорость роста $\mathrm{AlGaAs}$ поддерживалась постоянной и составляла 1 монослой в секунду.

Исследования морфологических свойств выращенных образцов были выполнены с помощью растрового электронного микроскопа (РЭМ) Zeiss Supra 25. Оптические свойства ННК были изучены методом микрофотолюминесценции при температуре $4 \mathrm{~K}$. Возбуждение сигнала от одиночных ННК осуществлялось лазером (длина волны $532 \mathrm{~nm}$ ) при диаметре лазерного пятна на поверхности образца $1 \mu \mathrm{m}$. Для регистрации сигнала использовался Si-детектор. Оптический микроскоп, установленный внутри криостата, позволял контролировать in situ поверхность образца в области возбуждения лазером.

На рис. 1 представлены РЭМ-изображения синтезированных структур. Из рисунка видно, что сформировались HНК AlGaAs высотой $\sim 2 \mu \mathrm{m}$ строго в направлении $\langle 111\rangle$, что свидетельствует об их эпитаксиальной связи с подложкой $\mathrm{Si}$. При этом средний диаметр ННК составил $100 \mathrm{~nm}$. Поверхностная плотность ННК, соответствую- щая плотности капель золота на поверхности подложки, оказалась равна $3 \cdot 10^{-7} \mathrm{~cm}^{-2}$. Подобная плотность позволяла возбуждать одиночный ННК на отдельных участках подложки. Помимо этого на поверхности подложки между ННК наблюдается квазидвумерный слой AlGaAs.

Для сравнения интенсивности излучения из КТ в разных направлениях часть стоящих на подложке ННК была удалена с поверхности подложки и уложена на поверхность чистой кремниевой пластины.

На рис. 2 продемонстрированы типичные спектры микрофотолюминесценции при одинаковых условиях, соответствующие излучению от КТ GaAs в одиночном HНK AlGaAs, выращенном в направлении, перпендикулярном поверхности $\mathrm{Si}$-подложки $(a)$, а также в диспергированном на поверхности $\mathrm{Si}$ одиночном ННК $(b)$. При этом в обоих случаях сбор сигнала фотолюминесценции от наноструктур производился в направлении, перпендикулярном поверхности подложки. На вставке к рис. 2, $b$ показано изображение лежащего на поверхности $\mathrm{Si}$ ННК, выполненное с помощью оптического микроскопа во время регистрации спектров микрофотолюминесценции. Как следует из рисунков, длины волн максимумов пиков спектров микрофотолюминесценции в обоих случаях практически совпадают и составляют $\sim 795 \mathrm{~nm}$. Однако интенсивность микрофотолюминесценции от лежащих на поверхности наноструктур примерно на два порядка меньше, чем от не удаленных с поверхности подложки ННК. При этом важно отметить, что при отсутствии ННК в пределах лазерного пучка сигнал микрофотолюминесценции не наблюдался. Этот факт исключает влияние формирующегося при синтезе ННК квазидвумерного слоя на полученные спектры микрофотолюминесценции. Все отмеченное выше указывает на направленность излучения микрофотолюминесценции из KT GaAs в теле HНK AlGaAs в направлении 

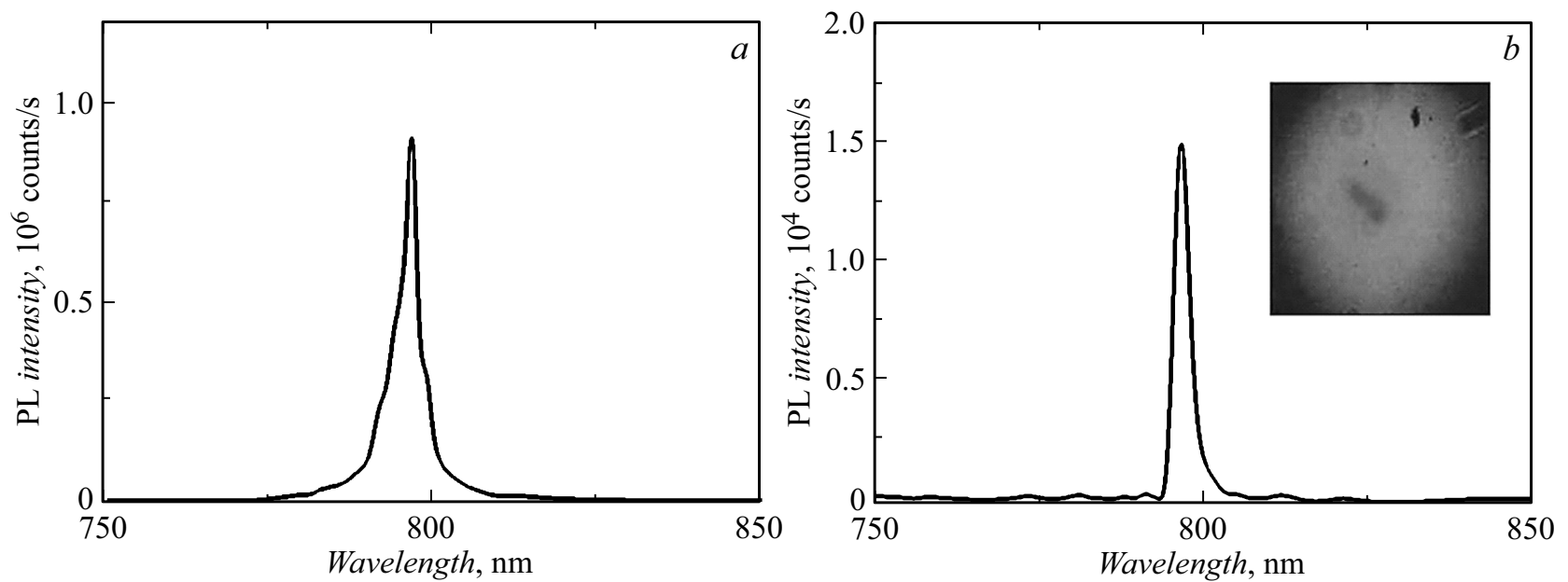

Рис. 2. Типичные спектры микрофотолюминесценции при $4 \mathrm{~K}$ от КТ GaAs в одиночных HНK AlGaAs: $a$ - в выращенном в направлении, перпендикулярном поверхности $\mathrm{Si}$-подложки; $b-$ в уложенном параллельно поверхности $\mathrm{Si}$. На вставке приведено изображение лежащего на поверхности $\mathrm{Si}$ одиночного ННК, выполненное с помощью оптического микроскопа.

роста ННК. Для более глубокого исследования данного явления в последующих работах будут проведены теоретические расчеты и экспериментальные исследования диаграммы направленности излучения из КТ GaAs в HHK AlGaAs.

Таким образом, в результате исследований было показано, что интенсивность излучения из КТ GaAs в теле HHK AlGaAs в направлении роста НHК на два порядка превышает интенсивность излучения из КТ в направлении, перпендикулярном росту ННК. Следовательно, HHK AlGaAs c KT GaAs являются перспективными объектами для использования в качестве наноисточников направленного излучения.

\section{Финансирование работы}

Синтез структур был выполнен при поддержке Министерства науки и высшего образования в части государственного задания № 0791-2020-0003. Исследования структурных свойств экспериментальных образцов проводились при финансовой поддержке Санкт-Петербургского государственного университета (исследовательский грант № 61520973). Исследования оптических свойств экспериментальных образцов осуществлялись при финансовой поддержке European Union's Horizon 2020 research and innovation program under the Marie Skłodowska-Curie Grant Agreement № 722176 (INDEED). Подготовка кремниевых подложек выполнялась при поддержке Российского научного фонда (грант № 18-7210047).

\section{Конфликт интересов}

Авторы заявляют, что у них нет конфликта интересов.

\section{Список литературы}

[1] В.Г. Дубровский, Г.Э. Цырлин, В.М. Устинов, ФТП, 43 (12), 1581 (2009). [Пер. версия: 10.1134/s106378260912001x].

[2] G.E. Cirlin, V.G. Dubrovskii, Yu.B. Samsonenko, A.D. Bouravleuv, K. Durose, Y.Y. Proskuryakov, B. Mendes, L. Bowen, M.A. Kaliteevski, R.A. Abram, D. Zeze, Phys. Rev. B, 82 (3), 035302 (2010). DOI: 10.1103/PhysRevB.82.035302

[3] A. Ignatiev, A. Freundlich, O. Pchelyakov, A. Nikiforov, L. Sokolov, D. Pridachin, V. Blinov, in Molecular beam epitaxy: from research to mass production (Elsevier, 2018), p. 741-749. DOI: 10.1016/B978-0-12-812136-8.00035-9

[4] Р.Р. Резник, Г.Э. Цырлин, И.В. Штром, А.И. Хребтов, И.П. Сошников, Н.В. Крыжановская, Э.И. Моисеев, А.Е. Жуков, Письма в ЖТФ, 44 (3), 55 (2018). DOI: 10.21883/PJTF.2018.03.45579.16991

[5] D. Dalacu, K. Mnaymneh, J. Lapointe, X. Wu, P.J. Poole, G. Bulgarini, V. Zwiller, M.E. Reimer. Nano Lett., 12 (11), 5919 (2012). DOI: 10.1021/n1303327h

[6] G.E. Cirlin, R.R. Reznik, I.V. Shtrom, A.I. Khrebtov, I.P. Soshnikov, S.A. Kukushkin, L. Leandro, T. Kasama, N. Akopian, J. Phys. D: Appl. Phys., 50 (48), 484003 (2017). DOI: $10.1088 / 1361-6463 /$ aa9169

[7] J. Renard, R. Songmuang, C. Bougerol, B. Daudin, B. Gayral, Nano Lett., 8 (7), 2092 (2008). DOI: 10.1021/n10800873

[8] V.G. Dubrovskii, G.E. Cirlin, V.M. Ustinov, Phys. Rev. B, 68 (7), 075409 (2003). DOI: 10.1103/PhysRevB.68.075409

[9] L. Leandro, C.P. Gunnarsson, R. Reznik, K.D. Jöns, I. Shtrom, A. Khrebtov, T. Kasama, V. Zwiller, G. Cirlin, N. Akopian, Nano Lett., 18 (11), 7217 (2018). DOI: $10.1021 /$ acs.nanolett.8b03363

[10] L. Leandro, J. Hastrup, R. Reznik, G. Cirlin, N. Akopian, npj Quantum Inf., 6 (1), 93 (2020). DOI: $10.1038 / \mathrm{s} 41534-020-00323-9$

[11] L. Leandro, R. Reznik, J.D. Clement, J. Repän, M. Reynolds, E.V. Ubyivovk, I.V. Shtrom, G. Cirlin, N. Akopian, Sci. Rep., 10 (1), 735 (2020). DOI: 10.1038/s41598-020-57563-0 
[12] В.Г. Талалаев, И.В. Штром, Ю.Б. Самсоненко, А.И. Хребтов, А.Д. Буравлев, Г.Э. Цырлин, Письма в ЖТФ, 43 (17), 71 (2017). DOI: 10.21883/PJTF.2017.17.44949.16504

[13] G. Bulgarini, M.E. Reimer, T. Zehender, M. Hocevar, E.P. Bakkers, L.P. Kouwenhoven, V. Zwiller, Appl. Phys. Lett., 100 (12), 121106 (2012). DOI: 10.1063/1.3694935

[14] A. Jaffal, W. Redjem, P. Regreny, H.S. Nguyen, S. Cueff, X. Letartre, P. Patriarche, E. Rousseau, G. Cassabois, M. Gendry, N. Chauvin, Nanoscale, 11 (45), 21847 (2019). DOI: 10.1039/C9NR06114B 